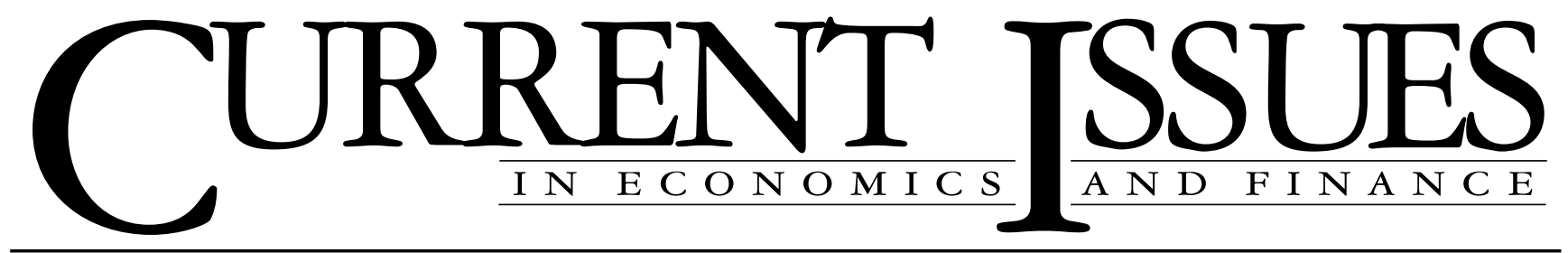

June 1996

Volume 2 Number 7

\title{
The Yield Curve as a Predictor of U.S. Recessions
}

\author{
Arturo Estrella and Frederic S. Mishkin
}

The yield curve-specifically, the spread between the interest rates on the ten-year Treasury note and the three-month Treasury bill_-is a valuable forecasting tool. It is simple to use and significantly outperforms other financial and macroeconomic indicators in predicting recessions two to six quarters ahead.

Economists often use complex mathematical models to forecast the path of the U.S. economy and the likelihood of recession. But simpler indicators such as interest rates, stock price indexes, and monetary aggregates also contain information about future economic activity. In this edition of Current Issues, we examine the usefulness of one such indicator-the yield curve or, more specifically, the spread between the interest rates on the ten-year Treasury note and the three-month Treasury bill. To get a sense of the relative power of this variable, we compare it with other financial and macroeconomic variables used to predict economic events.

Our analysis differs in two important respects from earlier studies of the predictive power of financial variables. ${ }^{1}$ First, we focus simply on the ability of these variables to forecast recessions rather than on their success in producing quantitative measures of future economic activity. We believe this is a useful approach because evidence of an oncoming recession is of clear interest to policymakers and market participants. Second, we choose to examine out-of-sample, rather than in-sample, performance-that is, we look at accuracy in predictions for quarters beyond the period over which the model is estimated. This feature of our study is particularly important because out-of-sample performance provides a much truer test of an indicator's real-world forecasting ability.

\section{Why Consider the Yield Curve?}

The steepness of the yield curve should be an excellent indicator of a possible future recession for several reasons. Current monetary policy has a significant influence on the yield curve spread and hence on real activity over the next several quarters. A rise in the short rate tends to flatten the yield curve as well as to slow real growth in the near term. This relationship, however, is only one part of the explanation for the yield curve's usefulness as a forecasting tool. ${ }^{2}$ Expectations of future inflation and real interest rates contained in the yield curve spread also seem to play an important role in the prediction of economic activity. The yield curve spread variable examined here corresponds to a forward interest rate applicable from three months to ten years into the future. As explained in Mishkin (1990a, 1990b), this rate can be decomposed into expected real interest rate and expected inflation components, each of which may be helpful in forecasting. The expected real rate may be associated with expectations of future monetary policy and hence of future real growth. Moreover, because inflation tends to be positively related to activity, the expected inflation component may also be informative about future growth.

Although the yield curve has clear advantages as a predictor of future economic events, several other variables have been widely used to forecast the path of the 
economy. Among financial variables, stock prices have received much attention. Finance theory suggests that stock prices are determined by expectations about future dividend streams, which in turn are related to the future state of the economy. Among macroeconomic variables, the Commerce Department's (now the Conference Board's) index of leading economic indicators appears to have an established performance record in predicting real economic activity. Nevertheless, its record has not always been subjected to careful comparison tests. In addition, because this index has often been revised after the fact to improve its performance, its success could be overstated. An alternative index of leading indicators, developed in Stock and Watson (1989), appears to perform better than the Commerce Department's index of leading economic indicators. In the discussion below, we compare the predictive power of all three of these variables with that of the yield curve. $^{3}$

\section{Estimating the Probability of Recession}

To assess how well each indicator variable predicts recessions, we use the so-called probit model, which, in our application, directly relates the probability of being in a recession to a specific explanatory variable such as the yield curve spread. ${ }^{4}$ For example, one of the most successful models in our study estimates the probability of recession four quarters in the future as a function of the current value of the yield curve spread between the ten-year Treasury note and the three-month Treasury bill. The results of the model, based on data from the first quarter of 1960 to the first quarter of

\section{Estimated Recession Probabilities for Probit Model Using the Yield Curve Spread \\ Four Quarters Ahead}

\begin{tabular}{cc}
$\begin{array}{c}\text { Recession Probability } \\
\text { (Percent) }\end{array}$ & $\begin{array}{c}\text { Value of Spread } \\
\text { (Percentage Points) }\end{array}$ \\
\hline 5 & 1.21 \\
10 & 0.76 \\
15 & 0.46 \\
20 & 0.22 \\
25 & 0.02 \\
30 & -0.17 \\
40 & -0.50 \\
50 & -0.82 \\
60 & -1.13 \\
70 & -1.46 \\
80 & -1.85 \\
90 & -2.40
\end{tabular}

Note: The yield curve spread is defined as the spread between the interest rates on the ten-year Treasury note and the three-month Treasury bill.
1995, are presented in a table showing the values of the yield curve spread that correspond to estimated probabilities of a recession four quarters in the future. As the table indicates, the estimated probability of a recession four quarters ahead estimated from this

\section{The yield curve spread averaged -2.18 percentage points in the first quarter of 1981, implying a probability of recession of 86.5 percent four quarters later. As predicted, the first quarter of 1982 was in fact designated a recession quarter by the National Bureau of Economic Research.}

model is 10 percent when the spread averages 0.76 percentage points over the quarter, 50 percent when the spread averages -0.82 percentage points, and 90 percent when the spread averages -2.40 percentage points.

The usefulness of the model can be illustrated through the following examples. Consider that in the third quarter of 1994, the spread averaged 2.74 percentage points. The corresponding predicted probability of recession in the third quarter of 1995 was only 0.2 percent, and indeed, a recession did not materialize. In contrast, the yield curve spread averaged -2.18 percentage points in the first quarter of 1981, implying a probability of recession of 86.5 percent four quarters later. As predicted, the first quarter of 1982 was in fact designated a recession quarter by the National Bureau of Economic Research.

\section{Tracking the Performance of the Variables}

Using the results of our model, we can compare the forecasting performance of the yield curve spread with that of the New York Stock Exchange (NYSE) stock price index, the Commerce Department's index of leading economic indicators, and the Stock-Watson index. For each of these four variables, the chart on page 3 plots the forecasted probabilities of a recession in the United States for one, two, four, and six quarters in the future together with the actual periods of recession (the shaded areas)..$^{5}$

To understand how to read the chart, consider the forecast for the fourth quarter of 1990, which is the first quarter after the peak of the business cycle and is thus at the start of the last shaded recession region in each panel. In Panel 1, which shows the forecast one quarter ahead, the probability of recession from the probit model using the yield curve spread variable (Spread) forecasted in the third quarter of 1990 for the 
Forecasted Probability of Recession: A Comparison of Four Indicators
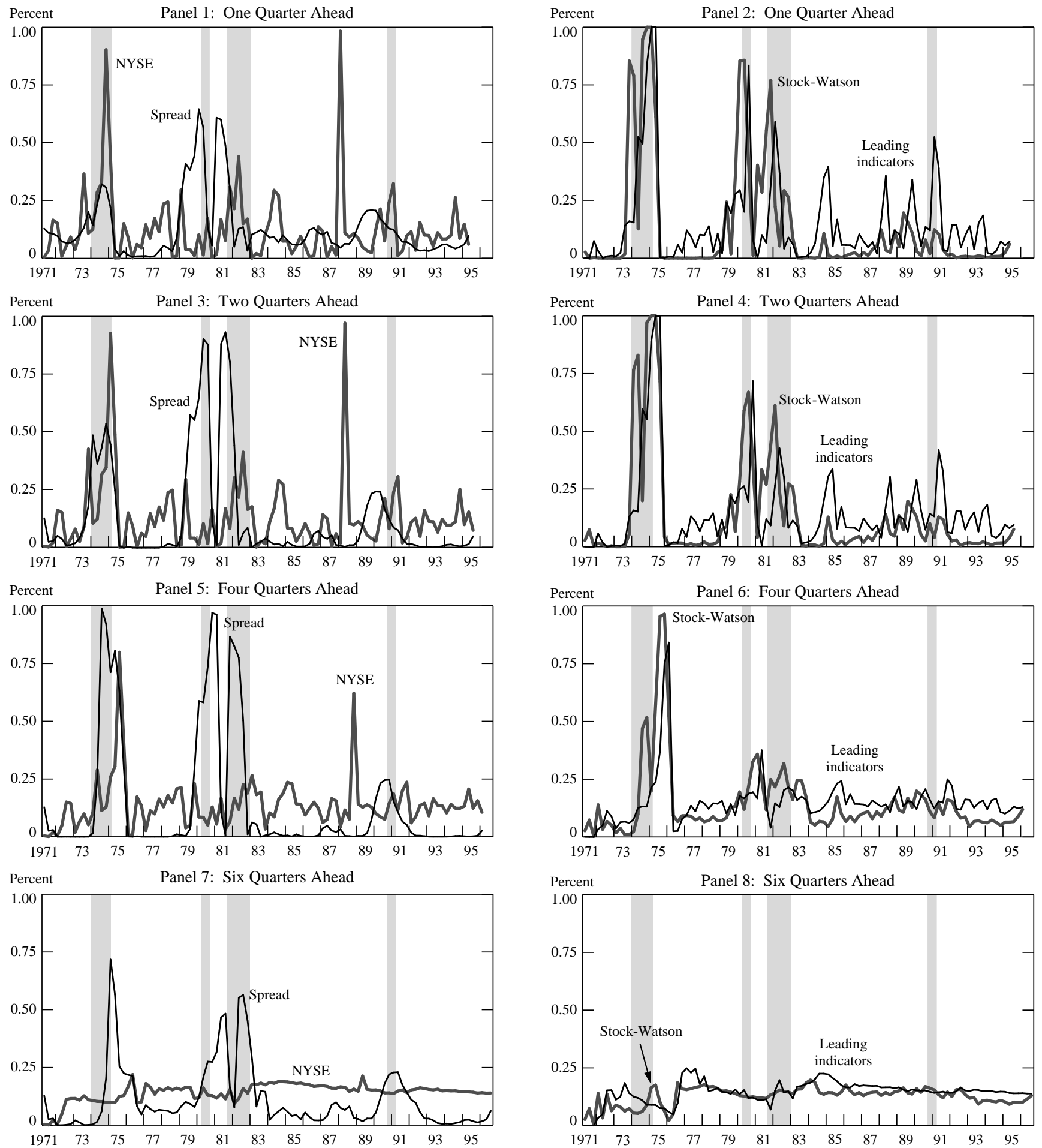

Source: Authors' calculations.

Notes: The probabilities in this chart are derived from out-of-sample forecasts one, two, four, and six quarters ahead. For example, the forecasted probabilities in Panels 1 and 2 are for one quarter ahead - that is, the probability shown is a forecast for the quarter indicated, using data from one quarter earlier-while for Panels 7 and 8 , the forecasted probabilities are for six quarters ahead. Spread denotes the forecasts from the model using the yield curve spread (the difference between the interest rates on ten-year Treasury notes and three-month Treasury bills, both on a bond-equivalent basis) as the explanatory variable. NYSE denotes the results from the model using the quarterly percentage change in the New York Stock Exchange stock price index as the explanatory variable. Leading indicators denotes the forecasts from the model using the quarterly percentage change in the Commerce Department's (now the Conference Board's) index of leading indicators as the explanatory variable. Stock-Watson denotes the forecasts using the quarterly percentage change in the Stock-Watson (1989) leading economic indicator index as the explanatory variable. Shaded areas designate "recessions" starting with the first quarter after a business cycle peak and continuing through the trough quarter. The peak and trough dates are the standard ones issued by the National Bureau of Economic Research. 
fourth quarter of 1990 is 13 percent. Similarly, in Panel 7, which shows forecasts six quarters ahead, the forecasted probability of recession for the fourth quarter of 1990-22 percent_-is generated from a model using the yield curve spread as of the second quarter of 1989.

In assessing these panels, note that even a probability of recession that is considerably less than one can be a strong signal of recession. Because in any given quarter the probability of recession is quite low, a forecasted probability of, say, 50 percent is going to be quite unusual. Indeed, the successful forecasting model described in the table yields probabilities of recession that are typically below 10 percent in nonrecession (unshaded) periods (as shown in Panel 5). Thus, even a probability of recession of 25 percent-the figure forecast for the fourth quarter of 1990 from data on the yield curve spread one year earlier-was a relatively strong signal in the fourth quarter of 1989 that a recession might come one year in the future.

The chart invites two basic conclusions about the performance of the four variables: ${ }^{6}$

- Although all the variables examined have some forecasting ability one quarter ahead, the leading economic indicator indexes, particularly the Stock-Watson index, produce the best forecasts over this horizon.

- In predicting recessions two or more quarters in the future, the yield curve dominates the other variables, and this dominance increases as the forecast horizon grows.

Let's look in more detail at the probability forecasts in Panels 1-8. Panels 1 and 2 show that the indexes of leading economic indicators typically outperform the yield curve spread and the NYSE stock price index for forecasts one quarter ahead. For the 1973-75, 1980, and 1981-82 recessions, both indexes of leading economic indicators, and particularly the Stock-Watson index, are quite accurate, outperforming the yield curve spread and the NYSE stock price index with a high predicted probability during the recession periods. However, despite excellent performance in these earlier recessions, the Commerce Department indicator provides several incorrect signals in the 1982-90 boom period, and the Stock-Watson index completely misses the most recent recession in 1990-91. ${ }^{7}$ Although the financial variables - the yield curve spread and the NYSE stock price index - are not quite as accurate as the leading economic indicators in predicting the 1973-75, 1980, and 1981-82 recessions one quarter ahead, they do provide a somewhat clearer signal of an imminent recession in 1990.
As the forecasting horizon lengthens to two quarters ahead and beyond, the performance of the NYSE stock price index and the leading economic indicator indexes deteriorates substantially (Panels 3-8). Indeed, at a sixquarter horizon, the probabilities estimated using the three indexes are essentially flat, indicating that these variables have no ability to forecast recessions. In contrast, the performance of the yield curve spread

\section{The performance of the yield curve spread improves considerably as the forecast horizon lengthens to two and four quarters.}

improves considerably as the forecast horizon lengthens to two and four quarters. The estimated probabilities of recession for 1973-75, 1980, and 1981-82 based on the yield curve spread are substantially higher than at the one-quarter horizon, and the signal for the 1981-82 recession no longer comes too early (compare Panel 5 with Panel 1).

Furthermore, in contrast to the other variables, the yield curve spread gives a relatively strong signal in forecasting the 1990-91 recession four quarters ahead. Although the forecasted probability is lower than in previous recessions, it does reach 25 percent (Panel 5).

There are two reasons why the signal for this recession may have been weaker than for the earlier recessions. First, restrictive monetary policy probably induced the 1973-75, 1980, and 1981-82 recessions, but it played a much smaller role in the 1990-91 recession. Because the tightening of monetary policy also affects the yield curve, we would expect the signal to be more pronounced at such times. Second, the amount of variation in the yield curve spread has changed over time and was much less in the 1990s than in the early 1980s, making a strong signal for the 1990-91 recession difficult to obtain. ${ }^{8}$

When we look at how well the yield curve spread forecasts recessions six quarters in the future (Panel 7), we see that the performance deteriorates from the fourquarter-ahead predictions. Nonetheless, unlike the other variables considered, the yield curve spread continues to have some ability to forecast recessions six quarters ahead.

\section{Conclusion}

This article has examined the performance of the yield curve spread and several other financial and macroeconomic variables in predicting U.S. recessions. The 
results obtained from a model using the yield curve spread are encouraging and suggest that the yield curve spread can have a useful role in macroeconomic prediction, particularly with longer lead times. Policymakers value longer term forecasts because policy actions typically take effect on the economy with long time lags. Thus, the fact that the yield curve strongly outperforms other variables at longer horizons makes its use as a forecasting tool even more compelling.

With the existence of large-scale macroeconometric models and the judgmental assessments of knowledgeable market observers, why should we care about the predictive ability of the yield curve? There is no question that judgmental and macroeconometric forecasts are quite helpful. Nevertheless, the yield curve can usefully supplement large econometric models and other forecasts for three reasons. First, forecasting with the yield curve has the distinct advantage of being quick and simple. With a glance at the ten-year note and three-month bill rates on the computer screen, anyone can compute a probability forecast of recession almost instantaneously by using a table such as ours.

Second, a simple financial indicator such as the yield curve can be used to double-check both econometric and judgmental predictions by flagging a problem that might otherwise have gone unidentified. For example, if forecasts from an econometric model and the yield curve agree, confidence in the model's results can be enhanced. In contrast, if the yield curve indicator gives a different signal, it may be worthwhile to review the assumptions and relationships that led to the prediction. Third, using the yield curve to forecast within the framework outlined here produces a probability of future recession, a probability that is of interest in its own right.

\section{Notes}

1. A list of references on this literature can be found in Estrella and Mishkin (1996).

2. The analyses in Estrella and Hardouvelis (1990, 1991) and Estrella and Mishkin (1995) suggest why the yield curve contains information beyond that related to monetary policy.

3. In Estrella and Mishkin (1996), we have examined in detail the predictive ability of these and other variables, including interest rates by themselves, other stock market indexes, interest rate spreads, monetary aggregates (both nominal and real), the component series of the index of leading economic indicators, and an additional experimental index of leading indicators developed in Stock and Watson (1992). Of all the variables, the four singled out in this article have the best ability to predict recessions.

4. For a technical discussion of this model and how it is estimated, see Estrella and Mishkin (1996). The economy is designated as "in recession" starting with the first quarter after a business cycle peak and continuing through the trough quarter. The peak and trough dates are the standard ones issued by the National Bureau of Economic Research (NBER) and used in most business cycle analysis. These dates are not without controversy, however, because the NBER methodology makes implicit assumptions in arriving at these dates.

5. Note that the forecasts in these panels are true out-of-sample results, obtained in the following way: First, a given model is estimated using past data up to a particular date, say the first quarter of 1970. Then these estimates are used to form the forecasts, say four quarters ahead. In this case, the projection would apply to the first quarter of 1971. After adding one more quarter to the estimation period, the procedure is repeated. That is, data up to the second quarter of 1970 are used to make a forecast for the second quarter of 1971. In this way, the procedure mimics what a forecaster would have predicted with the information available at any point in the past.

6. Note that all conclusions drawn from looking at the charts are confirmed by more precise statistical measures of out-of-sample fit in Estrella and Mishkin (1996).

7. These results have already been noted in very useful postmortem analyses by Watson (1991) and Stock and Watson (1992).

8. Another potential explanation is that the 1990-91 recession was relatively mild and so a weaker signal might be expected. However, as shown in Estrella and Hardouvelis (1991), the yield curve spread also provides much weaker signals for recessions in the 1950s, even though they were not mild. Furthermore, the signal for the 1969-70 recession is strong, although the recession itself was mild. Thus, the severity of the recessions does not seem to be associated with the strength of the signal from the yield curve.

\section{References}

Estrella, Arturo, and Gikas Hardouvelis. 1990. "Possible Roles of the Yield Curve in Monetary Analysis." In Intermediate Targets and Indicators for Monetary Policy, Federal Reserve Bank of New York.

1991. "The Term Structure as a Predictor of Real Economic Activity." Journal of Finance 46, no. 2 (June).

Estrella, Arturo, and Frederic S. Mishkin. 1995. "The Term Structure of Interest Rates and Its Role in Monetary Policy for the European Central Bank." National Bureau of Economic Research Working Paper no. 5279, September.

__ 1996. "Predicting U.S. Recessions: Financial Variables as Leading Indicators." Federal Reserve Bank of New York Research Paper no. 9609, May.

Mishkin, Frederic S. 1990a. "What Does the Term Structure Tell Us About Future Inflation?” Journal of Monetary Economics 25 (January): 77-95.

—_. 1990b. "The Information in the Longer-Maturity Term Structure About Future Inflation." Quarterly Journal of Economics 55 (August): 815-28.

Stock, James, and Mark Watson. 1989. "New Indexes of Coincident and Leading Indicators." In Olivier Blanchard and Stanley Fischer, eds., NBER Macroeconomic Annual 4. 
1992. "A Procedure for Predicting Recessions with Leading Indicators: Econometric Issues and Recent Performance." Federal Reserve Bank of Chicago Working Paper WP-92-7, April.
Watson, Mark. 1991. "Using Econometric Models to Predict Recessions." Federal Reserve Bank of Chicago Economic Perspectives 15, no. 6 (November-December).

\section{About the Authors}

Arturo Estrella is Vice President in the Capital Markets Function of the Research and Market Analysis Group. Frederic S. Mishkin is Executive Vice President and Director of Research for the Bank.

The views expressed in this article are those of the authors and do not necessarily reflect the position of the Federal Reserve Bank of New York or the Federal Reserve System.

\section{Recent Current Issues}

\begin{tabular}{|c|c|c|c|}
\hline Date & Vol./No. & Title & Author(s) \\
\hline $1 / 96$ & $2 / 1$ & Coping with the Rising Yen: Japan's Recent Export Experience & Klitgaard \\
\hline $2 / 96$ & $2 / 2$ & Dynamics of the Second District Economy & Bram \\
\hline $3 / 96$ & $2 / 3$ & $\begin{array}{l}\text { Small Business Lending and Bank Consolidation: } \\
\text { Is There Cause for Concern? }\end{array}$ & Strahan, Weston \\
\hline $4 / 96$ & $2 / 4$ & Core CPI: Excluding Food, Energy ... and Used Cars? & Peach, Alvarez \\
\hline $4 / 96$ & $2 / 5$ & 1996 Job Outlook: The New York-New Jersey Region & Orr, Rosen \\
\hline $5 / 96$ & $2 / 6$ & Understanding Aggregate Default Rates of High Yield Bonds & Helwege, Kleiman \\
\hline
\end{tabular}

Readers interested in obtaining copies of Current Issues in Economics and Finance through the Internet can visit our site on the World Wide Web (http://www.ny.frb.org). From the Bank's research publications page, you can view, download, and print any edition in the Current Issues series, as well as articles from the Economic Policy Review. You can also view abstracts for Staff Reports and Research Papers and order the full-length, hard-copy versions of them electronically.

Current Issues in Economics and Finance is published by the Research and Market Analysis Group of the Federal Reserve Bank of New York. Dorothy Meadow Sobol is the editor.

Editorial Staff: Valerie LaPorte, Mike De Mott, Elizabeth Miranda Production: Graphics and Publications Staff

Subscriptions to Current Issues are free. Write to the Public Information Department, Federal Reserve Bank of New York, 33 Liberty Street, New York, N.Y. 10045-0001, or call 212-720-6134. Back issues are also available. 